\title{
EFFECTS OF MOISTURE-DEPENDENT PROPERTIESOF CONSTITUENTS ON THE HYGROSCOPIC STRESSES IN COMPOSITE STRUCTURES
}

\author{
G. Youssef, S. Fréour, and F. Jacquemin \\ Institut de Recherche en Génie Civil et Mécanique (UMR CNRS 6183), Université de Nantes, Ecole Centrale de Nantes, France
}

The effects related to the evolution of the moisture-dependent hygroelastic properties of composite plies constituting a fiber-reinforced epoxy laminate on the predicted stress states in the structure during the transient stage of hygroscopic loading are investigated. The approach proposed involves the coupling of the classical continuum mechanics formalism to the Eshelby-Kröner self-consistent scale transition model. An inverse scale transition model is used to describe the evolution of local hygroelastic properties of the epoxy matrix as the process of moisture diffusion proceeds. The scale transition relations allow one to determine the local distribution of stresses in the constituents (fiber and matrix) of each ply of the laminates considered from the distribution of macroscopic stresses. Numerical simulations show that the account (or not) of softening of the composite structure under hygroscopic loadings significantly affects the multiscale stress states predicted.

Keywords: composite laminates, moisture diffusion, hygroscopic stresses, softening, modeling

\section{Introduction}

Carbon-reinforced epoxy matrix composites provide an answer to the needs for weight reduction and design flexibility in many industrial applications, such as, e.g., for the mechanical parts of airplanes. Composite structures are often submitted to various environmental conditions during their service life, including thermal and hygroscopic loadings. Actually, carbon/epoxy composites can absorb a significant amount of water and exhibit nonuniform coefficients of thermal expansion (CTE) (i.e., the CTE of the epoxy matrix strongly differ from the CTE of carbon fibers), as shown in [1-3]. Moreover, the diffusion of moisture in such materials is a rather slow process, resulting in moisture concentration gradients within their depth, during at least the transient stage [4]. As a consequence, local stresses arise under hygroscopic loading of composite structures, which depend on environmental conditions, on the local intrinsic properties of their constituents, and on their microstructure (the morphology of constituents, the lay-up configuration, etc.). The knowledge of internal stresses is necessary to predict the possible rise of damage in the material during its manufacture or service life. Thus, studies on the development of internal stresses in composites due to hygroelastic loads are very important in regard to any engineering application. Moreover, it is reported in the literature that the moisture diffusion in composite structures entails a significant softening of composite plies [5]. 
The present work is a part of a research project dedicated to the numerical determination of internal stresses in the constituents of carbon-fiber-reinforced epoxy composite structures, submitted to hygroscopic loading, during the transient stage of the moisture diffusion process. This communication is especially focused on investigating the effects related to the evolution of elastic stiffness of the epoxy resin as a function of moisture content in it. The relationship between the properties of constituents and the moisture content was determined from the evolution of corresponding macroscopic properties of a composite ply during the transient stage of the moisture diffusion process. The identification procedure involved an inverse self-consistent hygroelastic scale transition model, which is described in the second section of this article. In the third section, a multiscale analysis of the transient hygromechanical behavior of various composite structures submitted to hygroscopic loads is presented. The approach employs the formalism of continuum mechanics to determine the macroscopic stresses and strains as functions of time and spatial coordinates during the transient phase of the moisture diffusion process. In the fourth part of this study, the stresses and strains predicted with account of moisture-dependent material properties are compared with the reference values obtained by neglecting the influence of moisture.

\section{Inverse Scale Transition Modeling to Identify the Hygroelastic Properties of Individual Constituents of a Composite Ply}

\subsection{Introduction}

The knowledge of local properties of each constituent of a composite structure is necessary to predict its behavior through the use of scale transition models. Nevertheless, the stiffness and the coefficients of moisture expansion of the matrix and reinforcement are not always available in the literature. The practical determination of the hygromechanical properties of composite materials is most often performed on unidirectionally reinforced composites, whereas the properties of unreinforced matrices are easily found by direct measurements [6-11]. In spite of the existence of several articles dedicated to the characterization of the properties of an isolated reinforcement element [12-14], the available published data for typical reinforcing particulates employed in composite designs are still very limited. As a consequence, the properties of individual reinforcing element are not often known from direct experiments, but are usually deduced from the properties of a pure matrix and of a composite ply (which are determined more easily) through appropriate calculation procedures. In the present case, the literature provides data for the moisture-dependent elastic moduli of unidirectional fiber-reinforced plies [5], but not for the corresponding properties of their constituents. Thus, a dedicated identification method is necessary before proceeding further. The problem of determining the properties of constituents of heterogeneous materials has been extensively addressed in the field of materials science, especially for studying complex polycrystalline metallic alloys (like titanium alloys [15-17]) or metal matrix composites (typically aluminum-silicon carbide composites [18-19], or iron oxides from the inner core of Earth [20], for instance). The calculation methods employed to achieve this goal are either based on a finite-element analysis [21] or on the inversion of scale transition homogenization procedures [15-19]. The latter method is also used in the present work.

\subsection{Estimating constituent properties by the Eshelby-Kröner self-consistent inverse scale transition model}

\subsubsection{Introduction}

Scale transition models are based on a multiscale representation of materials. In the case of composite materials, a two-scale model is sufficient. In this model,

- the properties and mechanical states of the resin and reinforcement are indicated by the superscripts $m$ and $r$, respectively; these constituents define the so-called "pseudomacroscopic" scale of the material;

- the homogenization operations performed over the aforementioned constituents are assumed to provide the effective behavior of the composite ply, which defines the macroscopic scale of the model and is denoted by the superscript $I$. 
TABLE 1. Experimental Macroscopic Elastic Moduli at Elevated Moisture Contents and Temperatures according to [41]

\begin{tabular}{c|c|c|c|c|c|c}
\hline \multicolumn{2}{c|}{ Macroscopic hygrothermal load } & \multicolumn{5}{|c}{ Macroscopic elastic moduli } \\
\hline$\Delta C^{I}, \%$ & $T^{I}, \mathrm{~K}$ & $Y_{1}^{I}, \mathrm{GPa}$ & $Y_{2}^{I}, \mathrm{GPa}$ & $v_{12}^{I}$ & $G_{12}^{I}, \mathrm{GPa}$ & $G_{23}^{I}, \mathrm{GPa}$ \\
\hline 0 & 300 & 130 & 9.5 & 0.3 & 6.0 & 3.0 \\
0.25 & 300 & 130 & 9.25 & 0.3 & 6.0 & 3.0 \\
0.75 & 300 & 130 & 8.75 & 0.3 & 6.0 & 3.0 \\
0 & 325 & 130 & 8.5 & 0.3 & 6.0 & 3.0 \\
0 & 400 & 130 & 7.0 & 0.3 & 4.75 & 2.39 \\
\hline
\end{tabular}

TABLE 2. Pseudomacroscopic Elastic Moduli and Stiffness-Tensor Components of Carbon Fibers in Composite Plies at $\Delta C^{I}=0$ and $T^{I}=300 \mathrm{~K}$ According to the Inverse Eshelby-Kröner Self-Consistent Model in Comparison with Those of Typical Carbon Fibers [10]

\begin{tabular}{|c|c|c|c|c|c|c|}
\hline \multirow{2}{*}{ Model } & $Y_{1}^{r}$ & $Y_{2}^{r}$ & $G_{23}^{r}$ & $G_{12}^{r}$ & \multirow{2}{*}{$v_{12}^{r}$} & $L_{11}^{r}$ \\
\hline & \multicolumn{4}{|c|}{$\mathrm{GPa}$} & & GPa \\
\hline $\begin{array}{l}\text { Eshelby- } \\
\text { Kröner }\end{array}$ & 213.2 & 13.3 & 4.0 & 12.1 & 0.27 & 219.2 \\
\hline$[10]$ & 232 & 15 & 5,0 & 15 & 0.279 & 236.7 \\
\hline
\end{tabular}

\subsubsection{Estimating the effective properties of a composite ply by the Eshelby-Kröner self-consistent model}

Within the scale transition modeling, the local properties of the $i$-superscripted constituents are considered known (i.e., the pseudomacroscopic stiffnesses $L^{i}$ and the coefficients of moisture expansion $\beta^{i}$ ), whereas the corresponding effective macroscopic properties of the composite structure $\left(L^{i}\right.$ and $\beta^{i}$, respectively) are a priori unknown and are found by (often numerical) computations.

Among the numerous scale transition models available in the literature, the models elaborated by Voigt [22], Reuss [23], Neerfeld-Hill [24-25], Tsai-Hahn [26], and Mori-Tanaka [27-28] can be mentioned. However, they do not properly reflect the actual physical conditions experienced by the materials in practice. In the field of scale transition modeling, the best candidate remains the Kröner-Eshelby self-consistent model [29-30], because only this model takes into account the thermohygroelastic interactions between the homogeneous macroscopic medium and its heterogeneous constituents, as well as allows one to handle the microstructure of composites. The method was initially introduced to treat the case of polycrystalline materials in pure elasticity. The model was thereafter extended to thermoelastic loads and gave satisfactory results both for single-phase and two-phase materials [18-19]. More recently, this classical model was improved in order to treat problems related to hygroscopic loadings, and homogenization relations were established for estimating the macroscopic coefficients of moisture expansion [31]. The main equations used in determining the effective hygroelastic properties of heterogeneous materials according to the Eshelby-Kröner self-consistent approach are

$$
\mathbf{L}^{\mathbf{I}}=\left\langle\mathbf{L}^{\mathbf{i}}:\left(\mathbf{I}+\mathbf{E}^{\mathbf{I}}:\left[\mathbf{L}^{\mathbf{i}}-\mathbf{L}^{\mathbf{I}}\right]\right)^{-1}\right\rangle_{i=r, m},
$$


TABLE 3. Moisture- and Temperature-Dependent Pseudomacroscopic Elastic Moduli and Stiffness-Tensor Components of the Epoxy Matrix in Composite Plies according to the Inverse Eshelby-Kröner Self-Consistent Model

\begin{tabular}{c|c|c|c|c|c|c}
\hline \multirow{2}{*}{$\begin{array}{c}\text { Moisture } \\
\text { content } \\
\Delta C^{I}, \%\end{array}$} & \multirow{2}{*}{$\begin{array}{c}\text { Temperature } \\
T^{I}, \mathrm{~K}\end{array}$} & $Y^{m}$ & \multirow{2}{*}{$v^{m}$} & $G^{m}$ & $L_{11}^{m}$ & $L_{12}^{m}$ \\
\cline { 5 - 6 } & & $\mathrm{GPa}$ & & $\mathrm{GPa}$ & \multicolumn{2}{|c|}{$\mathrm{GPa}$} \\
\hline 0 & 300 & 5.35 & 0.35 & 1.98 & 8.62 & 4.67 \\
0.25 & 300 & 5.22 & 0.33 & 1.98 & 7.68 & 3.75 \\
0.75 & 300 & 4.95 & 0.28 & 1.98 & 6.29 & 2.41 \\
0 & 325 & 4.81 & 0.25 & 1.98 & 5.76 & 1.91 \\
0 & 400 & 4.17 & 0.27 & 1.04 & 5.20 & 1.92 \\
\hline
\end{tabular}

$$
\beta^{\mathbf{I}}=\frac{1}{\Delta C^{I}}\left\langle\left(\mathbf{L}^{\mathbf{i}}+\mathbf{L}^{\mathbf{I}}: \mathbf{R}^{\mathbf{I}}\right)^{-1}: \mathbf{L}^{\mathbf{I}}\right\rangle_{i=r, m}^{-1}:\left\langle\left(\mathbf{L}^{\mathbf{i}}+\mathbf{L}^{\mathbf{I}}: \mathbf{R}^{\mathbf{I}}\right)^{-1}: \mathbf{L}^{\mathbf{i}}: \beta^{\mathbf{i}} \Delta C^{i}\right\rangle_{i=r, m},
$$

where $\Delta C^{i}$ is the moisture content in an $i$ th element of the composite structure. The superscripts $r$ and $m$ replace the general superscript $i$ when properties of the reinforcement or matrix, respectively, have to be considered. The pseudomacroscopic moisture contents $\Delta C^{r}$ and $\Delta C^{m}$ can be expressed as functions of the macroscopic hygroscopic load $\Delta C^{I}$ [32].

In relations (1) and (2), the angle brackets stand for weighted volume averages. Hill [25] suggested the arithmetic or geometric averages for these operations. Both have been extensively used in the field of materials science. The interested reader is referred to [33-35], where the advantage of the geometric average is taken for estimating the properties and mechanical states of polycrystals, and to [19, 31,36], where the arithmetic average is employed. In [37], the geometric average was tested in estimating the effective properties of carbon-epoxy composites, but the results obtained were not so good as those obtained previously for metallic polycrystals or metal ceramic assemblies. Therefore, only the arithmetic average will be used in our investigation, where a composite consisting of a matrix and heterogeneous inclusions is considered. Introducing $v^{r}$ and $v^{m}$ as the volume fractions of ply constituents $\left(v^{r}+v^{m}=1\right)$, the volume average of any tensor $\mathbf{A}$ is expressed as

$$
\left\langle\mathbf{A}^{\mathbf{i}}\right\rangle_{i=r, m}=v^{\mathbf{r}} \mathbf{A}^{\mathbf{r}}+v^{m} \mathbf{A}^{\mathbf{m}} .
$$

According to Eqs. (1) and (2), the effective properties expressed by using the Eshelby-Kröner self-consistent model involve the so-called "reaction tensor" [36]

$$
\mathbf{R}^{\mathbf{I}}=\left(\mathbf{I}-\mathbf{S}_{\text {Esh }}^{\mathbf{I}}\right): \mathbf{S}_{\text {Esh }}^{\mathbf{I}}{ }^{-1}=\left(\mathbf{L}^{\mathbf{I}^{-1}}-\mathbf{E}^{\mathbf{I}}\right): \mathbf{E}^{\mathbf{I}^{-1}}
$$

Here, $\mathbf{I}$ is the fourth-order identity tensor; $\mathbf{E}^{\mathbf{I}}$ is the Hill tensor, also known as the Morris tensor [38], which relates the reaction tensor to the morphology assumed for the matrix and its reinforcement [39] and can be expressed as a function of the Eshelby tensor $\mathbf{S}_{\text {Esh }}^{\mathbf{I}}$ in the form $\mathbf{E}^{\mathbf{I}}=\mathbf{S}_{\text {Esh }}^{\mathbf{I}}: \mathbf{L}^{\mathbf{I}^{-1}}$. It should be emphasized that the Hill and Eshelby tensors are both functions of the macroscopic stiffness $\mathbf{L}^{\mathbf{I}}$ (some examples are given in [36, 40]). 


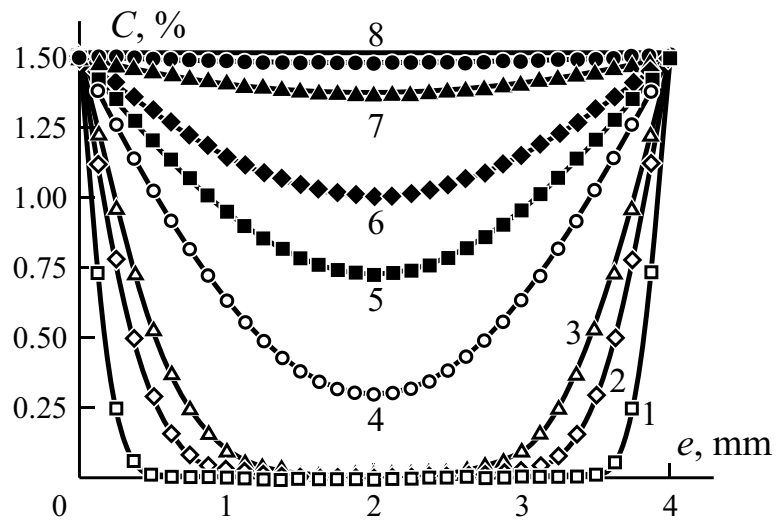

Fig. 1. Time- and space-dependent profiles of moisture content $C$ in the composite structure within 5 (1), 25 (2), 50 (3), 250 (4), 500 (5), 750 (6), 1500 (7), and 2500 (8) days; (-) - the permanent state.



Fig. 2. Time-dependent profile of the macroscopic transverse coefficient of moisture expansion $\beta_{22}$ within 5 (1), 50 (2), 250 (3), 500 (4), 750 (5), 1500 (6), and 2500 (7) days. (一) - the permanent state.

\subsubsection{Inverse Eshelby-Kröner self-consistent elastic model}

The pseudomacroscopic stiffness tensor of reinforcement can be deduced by inversion of the Eshelby-Kröner main homogenization form for the elastic properties of constituents (1) as follows:

$$
\mathbf{L}^{\mathbf{r}}=\frac{1}{v^{r}}\left[\mathbf{E}^{\mathbf{I}}:\left(\mathbf{L}^{\mathbf{r}}-\mathbf{L}^{\mathbf{I}}\right)+\mathbf{I}\right]-\frac{v^{m}}{v^{r}} \mathbf{L}^{\mathbf{m}}:\left[\mathbf{E}^{\mathbf{I}}:\left(\mathbf{L}^{\mathbf{m}}-\mathbf{L}^{\mathbf{I}}\right)+\mathbf{I}\right]^{-1}:\left[\mathbf{E}^{\mathbf{I}}:\left(\mathbf{L}^{\mathbf{r}}-\mathbf{L}^{\mathbf{I}}\right)+\mathbf{I}\right]
$$

The application of this equation implies that both the macroscopic stiffness and the pseudomacroscopic mechanical behavior of the matrix are known. The elastic stiffness of the matrix in the composite ply will be assumed identical to that determined experimentally on test specimens made of the matrix material. It was demonstrated in [15] that this assumption did not lead to significant errors.

An expression analogous to Eq. (3) can be written for the elastic stiffness of the matrix by performing the replacement of indices $m \rightarrow r$ and $r \rightarrow m$. 

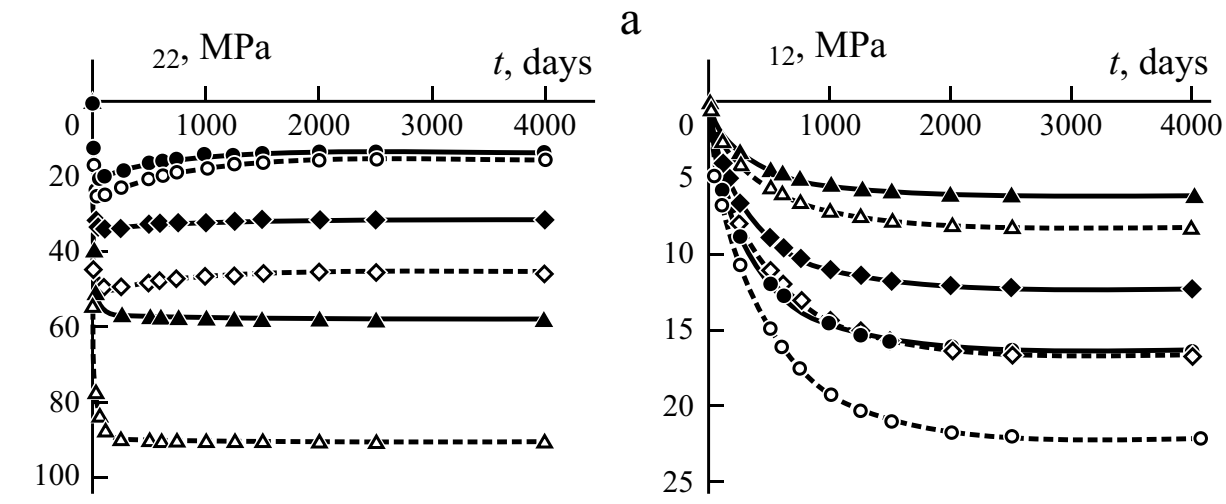

$\mathrm{b}$
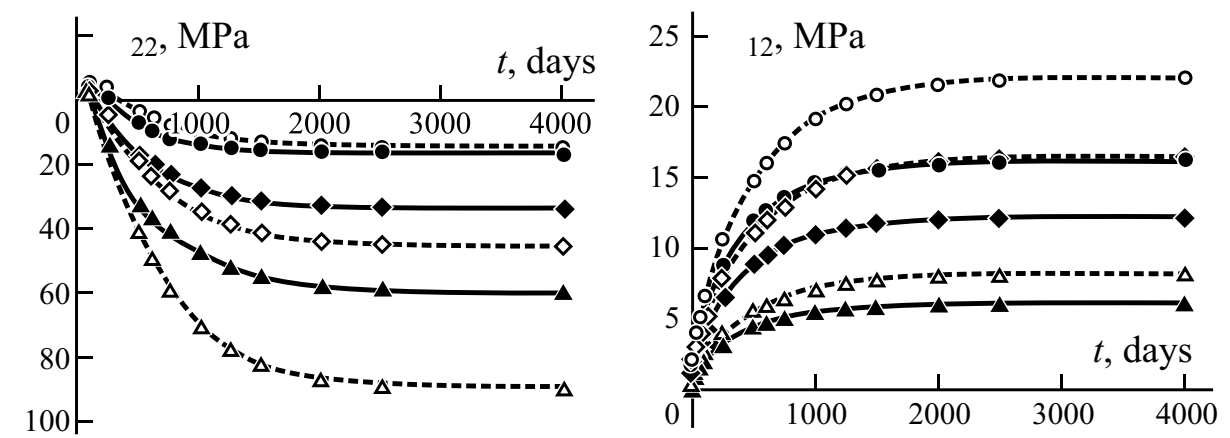

Fig. 3. Multiscale stress states in the external (a) and central (b) plies of a $[ \pm 55]$ composite during the transient stage of the moisture diffusion process: in the plies $(\diamond, \diamond)$, matrix $(\triangle, \mathbf{\Delta})$, and fibers $(\bigcirc, \bullet)$ with uniform (open symbols) and nonuniform (filled symbols) properties.

In the particular case of impermeable reinforcing elements in the composite structure, $\Delta C^{r}=0$. Then the pseudomacroscopic coefficients of moisture expansion of the matrix can be deduced by inversion of homogenization form (2) [31]:

$$
\beta^{\mathbf{m}}=\frac{\Delta C^{I}}{v^{m} \Delta C^{m}} \mathbf{L}^{\mathbf{m}^{-1}}:\left(\mathbf{L}^{\mathbf{m}}+\mathbf{L}^{\mathbf{I}}: \mathbf{R}^{\mathbf{I}}\right):\left\langle\left(\mathbf{L}^{\mathbf{i}}+\mathbf{L}^{\mathbf{I}}: \mathbf{R}^{\mathbf{I}}\right)^{-1}: \mathbf{L}^{\mathbf{I}}\right\rangle_{i=r, m}: \beta^{\mathbf{I}}
$$

\subsection{Application of the inverse scale transition model to determining the moisture- and temperature-dependent} pseudomacroscopic elastic properties of carbon-epoxy composites

The literature provides data for the elastic properties of various carbon-fiber-reinforced epoxy composites as functions of moisture concentration and temperature [5, 41]. Table 1 summarizes the data published in [45] for a unidirectional composite designed for aeronautic applications and containing reinforcing fibers with $v^{r}=0.60$. The variations in the macroscopic mechanical properties are obviously related to variations in the pseudomacroscopic elastic properties of constituents of the composite due to changing environmental conditions. It is usually assumed that carbon fibers do not absorb water, thus, there is no reason for expecting to link the elastic properties of the reinforcement to moisture content. Moreover, the thermomechanical properties of carbon fibers are almost independent of temperature, contrary to metals or polymers [18-19]. Furthermore, according to Table 1, the macroscopic longitudinal Young's modulus $Y_{1}^{I}$ is independent of environmental conditions in the ranges of temperature $T^{I}$ (from 300 to $400 \mathrm{~K}$ ) and macroscopic moisture content $C^{I}$ (from 0 to $0.75 \%$ ) studied, the 

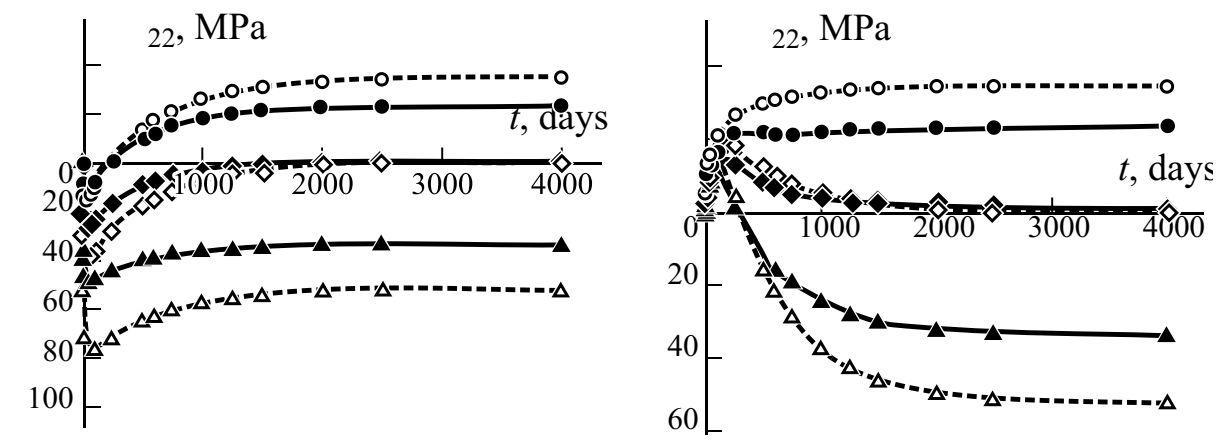

Fig. 4. The same for a unidirectional composite.

longitudinal direction being parallel to fibers. It is well known that the longitudinal macroscopic properties of such a unidirectional composite ply are governed by the pseudomacroscopic properties of fibers, whereas the transverse ones mainly depend on the pseudomacroscopic properties of matrix (see, for instance, $[10,26]$ ). Therefore, on the basis of the values presented in Table 1, it can be assumed that the elastic properties of the carbon fibers do not depend on environmental conditions. Thus, to a first approximation, the properties of the reinforcement can be considered invariable. Using the initial elastic properties of the dry epoxy matrix (Young's moduli $Y_{1}^{m}=Y_{2}^{m}=5.35 \mathrm{GPa}$, Poisson ratio $v_{12}^{m}=0.35$, shear moduli $G_{12}^{m}=G_{23}^{m}=1.98 \mathrm{GPa}$, and stiffness-tensor components $L_{11}^{m}=L_{22}^{m}=8.62 \mathrm{GPa}, L_{12}^{m}=4.66 \mathrm{GPa}$, and $\left.L_{44}^{m}=L_{55}^{m}=1.98 \mathrm{GPa}\right)$ and composite material $\left(\Delta C^{I}=\right.$ 0 in Table 1) at room temperature, the moisture- and temperature-independent properties of carbon fibers (Table 3) were found from Eq. (3). The decrease in $Y_{2}^{I}$ and $G_{12}^{I}$ with increasing temperature or moisture concentration (see Table 1) points to softening of the epoxy matrix.

Thus, the elastic moduli of the matrix should be identified for each available set of macroscopic data in order to find their susceptibility to hygrothermal conditions. Based on these data and the known properties of carbon fibers, the moistureand temperature-dependent elastic properties of the matrix (Table 4) were found from Eqs. (3) and (4). Owing to the lengthy moisture diffusion process, each ply of the composite structure will have hygroelastic properties different from those of neighboring plies during the transient stage of hygroscopic loading. The consequence of this physical phenomenon on the multiscale stress distribution in composite structures will be considered in the next section.

\section{Estimations of Multiscale Stresses in Composite Structures with}

\section{Account of Hygromechanical Coupling of the Elastic Stiffness: a}

\section{T300/5208 Composite Pipe under Environmental Conditions}

Thin laminated composite pipes with 4-mm-thick walls and fiber volume fraction $v^{r}=0.6$, made from T300/5208 carbon-epoxy plies, were considered for determining the macroscopic stresses and moisture content as functions of time and spatial coordinates.

The pipes were subjected to a symmetric hygroscopic loading corresponding to a relative humidity of $100 \%$ on each boundary of the structure (so that the final moisture content was equal to 1.5\%). The corresponding time-dependent profiles of moisture content, obtained by using Fick's law, are depicted in Fig. 1. From the time-dependent moisture content in each ply of the structure, the evolution of their macroscopic and local hygroelastic properties was calculated according to the method pro- 
posed in Sect. 2 of the present work. An example for the macroscopic transverse coefficient of moisture expansion of the composite plies constituting the cylinder is shown in Fig. 2. The moisture expansion coefficient of the matrix was considered constant during the diffusion process, and the variations observed in Fig. 2 were caused only by the moisture-dependent mechanical properties.

The closed-form formalism used to determine the mechanical stresses and strains in each ply of the structure induced by the distribution of moisture is described in [42]. The pseudomacroscopic stress and strain states in constituents of a given ply were determined from their macroscopic counterparts (taking into account the moisture content in the ply considered), invoking the analytical scale transition relations established in [43] on the basis of the fundamental analytical results published previously in [44]. Figures 3 and 4 show the numerical results obtained for the time-dependent multiscale distribution of transverse and shear stresses in $\pm 55^{\circ}$ laminates and unidirectional composites, respectively. In the unidirectionally reinforced structure, no shear stresses arise, so that the corresponding pictures are absent. In these figures, only the results obtained for the external and central plies of the hollow cylinder are depicted.

\section{Discussion of Results}

The results shown in Fig. 1 are similar to those published previously [31]: the transient stage of the (slow) moisture diffusion process in composite materials induces high gradients of moisture content within the thickness of the structure. The highest ones occur at the beginning of the diffusion process, and they decrease as the moisture content grows in the bulk of the structure: with time, the moisture content in the plies levels off.

Figure 2 provides some interesting additional results: the numerical simulation show high gradients for the macroscopic transverse coefficient of moisture expansion (caused only by the moisture-dependent elastic properties, since the moisture expansion coefficient of the matrix is considered constant), especially in the vicinity of the external and internal plies of the hollow cylinder studied, during the transient stage of the moisture diffusion process. The hygromechanical properties become the same at all scales when the permanent state is attained. Nevertheless, strong distinctions between the macroscopic and local properties still remain even at the saturation of the diffusion process, depending on the choice of the hypothesis for the relationship between the properties and moisture content.

According to Figs. 3 and 4, the account (or not) of changes in the hygroelastic properties of composite plies and their matrix strongly affects the level of transverse stresses and their distribution in the plies and their constituents. According to Fig. 3 , in the laminate, only the macroscopic stresses and those of the epoxy matrix significantly depend on the hypothesis assumed for material properties: the drop in the transverse Young's modulus of the matrix and ply during the moisture diffusion obviously decreases the transverse stresses induced by the hygroscopic load at the macroscopic scale and at the pseudomacroscopic scale in the epoxy matrix. The predicted stresses in the plies and their matrix can be reduced by up to $30 \%$ if the realistic evolution of material properties is taken into account.

Figure 4 depicts the classical results expected in the case where a unidirectional composite is subjected to a transient hygroscopic load: the high macroscopic stresses arising at the beginning of moisture diffusion thereafter decrease and disappear as soon as the permanent state is reached. However, the absolute values of the corresponding pseudomacroscopic transverse stresses increase almost uninterruptedly during the moisture diffusion process, reaching their maximum when the saturation state is attained. It should be emphasizes thad, in this specific case, the pseudomacroscopic transverse stress calculated for the carbon fiber vary significantly, depending on the choice of the hypothesis for the relationship between material properties and moisture content.

The macroscopic and local shear stresses are negative in the external ply and positive in the central one of the structure considered. According to Fig. 3, the account of the effect of moisture content on the material properties of composite plies has no influence on the concentration of shear stresses in the reinforcement, contrary to the case of transverse stresses considered previously. Of the three shear stresses calculated (i.e., in the ply, epoxy, and fibers), those in fibers were affected most by the 
hypothesis of possible evolution of material properties with moisture content, in spite of the fact that the properties of carbon fibers are in reality invariable during the moisture diffusion process. The lower local shear stresses in the carbon fibers are explained by the moisture-caused softening of composite plies.

According to the foresaid, the account of changes in the multiscale hygroelastic properties of composite plies has two main consequences that can be considered responsible for the reduced estimated stresses compared with their reference values (calculated disregarding the effect of moisture on material properties). First, sharp distinctions occur between the effective properties of the humid materials and their counterparts in the dry composite (see Fig. 2). This effect increases with time, as the amount of water in the structure grows, and reaches its maximum when the permanent stage of the diffusion process is attained. Since the predicted stresses are obviously intimately linked to the hygroelastic properties of the material, this effect partially explains the discrepancies between the two sets of curves displayed in Figs. 3 and 4. Second, gradients of moisture content arise in the composite during the transient stage of moisture diffusion in it, since the process is rather slow (see Fig. 1). The distribution of the hygroscopic load within depth of the structure directly induces a distribution of the hygroelastic properties of materials if their dependence on moisture content is taken into account in calculations. The nonuniform distribution of hygromechanical properties explains the distinctions occurring at the beginning of the moisture diffusion process between the internal stresses predicted with and without account of the effect of moisture on material properties. Thus, increased internal stresses, related to softening of the material induced by the diffusion of water, can be expected even at the beginning of hygroscopic loading of a composite structure.

\section{Conclusions and Prospects}

In this work, for the first time, the evolution of the macroscopic hygroelastic properties of composite plies as functions of moisture content in it is taken into account in a scale-transition-based approach dedicated to predicting the multiscale stress states in the plies and their constituents during the transient stage of hygroscopic loading of a composite structure. The scale transition approach involves the inversion of the classical homogenization procedure in order to estimate the evolution of the stiffness tensor of the epoxy matrix as a function of moisture content in it.

The mechanical states predicted with the model allowing for moisture-dependent material properties were compared with the reference values obtained assuming that material properties do not depend on moisture content. Numerical computations show that, as expected, the calculated longitudinal mechanical states of a ply (expressed in the reference frame of the ply) are the same whether or not the effect of moisture on material properties is considered. This result is understandable, because the hygromechanical behavior of carbon-fiber-reinforced composite plies is controlled by the longitudinal reinforcement. Since carbon fibers do not absorb water, their properties remain unchanged during the moisture diffusion process. Thus, the longitudinal properties and mechanical states are independent of interactions between the moisture content and hygroelastic properties of materials in fiber-reinforced composite structures. On the contrary, the estimated transverse and shear stresses, which strongly depend on the hygromechanical behavior of the matrix in composite plies, whose properties are moisture-dependent, can deviate from the reference values by up to $30 \%$.

Since the sizing of composite structures is strongly related to the internal state of stresses predicted for typical loads expected during their service life, the multiscale evolution of material properties as functions of moisture content, as demonstrated in the present study, cannot be neglected, at least for composite structures designed for operation in humid environments.

The next step along this line of research will deal with some additional physical factors in order to improve the reliability of predictions obtained by the scale transition models. For instance, in the present work, the moisture diffusion process was assumed to follow the classical, linear Fickian model. Nevertheless, some serious experimental results [45] have shown that certain anomalies in the moisture sorption process (deviations from the expected Fickian behavior) could be explained employ- 
ing the basic principles of irreversible thermodynamics, by considering the strong coupling between the moisture transport in polymers and local stress states [46-47]. The problem of hygromechanical coupling will be treated in our further investigations.

\section{REFERENCES}

1. S. W. Tsai, Composite Design, Think Composites (1987).

2. A. Agbossou and J. Pastor, "Thermal stresses and thermal expansion coefficients of $n$-layered fiber-reinforced composites," Compos. Sci. Technol., 57, 249-260 (1997).

3. P. D. Soden, M. J. Hinton, and A. S. Kaddour, "Lamina properties lay-up configurations and loading conditions for a range of fiber-reinforced composite laminates," Compos. Sci. Technol., 58, 1011-1022 (1998).

4. J. Crank, The Mathematics of Diffusion, Clarendon Press, Oxford (1975).

5. B. P. Patel, M. Ganapathi, and D. P. Makhecha, "Hygrothermal effects on the structural behaviour of thick composite laminates using higher-order theory," Compos. Struct., 56, 25-34 (2002).

6. D. E. Bowles, D. Post, C. T. Herakovich, and D. R. Tenney, "Moiré interferometry for thermal expansion of composites," Exp. Mech., 21, 441-447 (1981).

7. S. R. A. Dyer, D. Lord, I. J. Hutchinson, I. M. Ward, and R. A. Duckett, "Elastic anisotropy in unidirectional fibre reinforced composites," J. Phys. D: Appl. Phys., 25, 66-73 (1992).

8. C. Ferreira, P. Casari, R. Bouzidi, and F. Jacquemin, "Identification of Young's modulus profile in PVC foam core thickness using speckle interferometry and inverse method," in: Proc. SPIE — The International Society for Optical Engineering (2006).

9. C. Ferreira, F. Jacquemin, and P. Casari, "Measurement of the nonuniform thermal expansion coefficient of a PVC foam core by speckle interferometry - influence on the mechanical behavior of sandwich structures," J. Cell. Plast., 42, No. 5, 393-404 (2006).

10. C. T. Herakovitch, Mechanics of Fibrous Composites, John Wiley \& Sons Inc., New York (1998).

11. G. D. Sims, G. D. Dean, B. E. Read, and B. C. Western, "Assessment of damage in GRP laminates by stress wave emission and dynamic mechanical measurements," J. Mater. Sci., 12, No. 11, 2329-2342 (1997).

12. C. L. Tsai and I. M. Daniel, "Measurement of longitudinal shear modulus of single fibers by means of a torsional pendulum,” in: 38th Int. SAMPE Symp. (1993), pp. 1861-1868.

13. J. A. DiCarlo, "Creep of chemically vapor deposited SiC fiber," J. Mater. Sci., 21, 217-224 (1986).

14. C. L. Tsai and C. H. Chiang, "Characterization of the hygric behavior of single fibers," Compos. Sci. Technol., 60, 2725-2729 (2000).

15. S. Fréour, D. Gloaguen, M. Francois, R. Guillén, E. Girard, and J. Bouillo, "Determination of the macroscopic elastic constants of a phase embedded in a multiphase polycrystal - application to the beta-phase of Ti-17 titanium based alloy," Mater. Sci. Forum, 404-407, 723-728 (2002).

16. S. Fréour, D. Gloaguen, M. Francois, A. Perronnet, and R. Guillén, "Estimation of Ti-17 $\beta$-phase single-crystal elasticity constants using X-ray diffraction measurements and inverse scale transition modelling,” J. Appl. Crystallogr., 38, 30-37 (2005).

17. S. Fréour, D. Gloaguen, M. Francois, and R. Guillén, "Application of inverse models and XRD analysis to the determination of Ti-17 $\beta$-phase coefficients of thermal expansion," Scripta Mater., 54, 1475-1478 (2006).

18. S. Fréour, D. Gloaguen, M. Francois, and R. Guillén, "Study of the coefficients of thermal expansion of phases embedded in multiphase materials," Mater. Sci. Forum, 426-432, 2083-2088 (2003). 
19. S. Fréour, D. Gloaguen, M. Francois, and R. Guillén, "Thermal properties of polycrystals $-X$-ray diffraction and scale transition modelling," Phys. Stat. Solidi (a), 201, 59-71 (2003).

20. S. Matthies, S. Merkel, H. R. Wenk, R. J. Hemley, and H. Mao, "Effects of texture on the determination of elasticity of polycrystalline $\varepsilon$-iron from diffraction measurements," Earth Planet. Sci. Lett., 194, 201-212 (2001).

21. J. Han, A. Bertram, J. Olschewski, W. Hermann, and H. G. Sockel, "Identification of elastic constants of alloys with sheet and fibre textures based on resonance measurements and finite element analysis," Mater. Sci. Eng., A191, 105-111 (1995).

22. W. Voigt, Lehrbuch der Kristallphysik, Teubner, Leipzig-Berlin (1928).

23. A. Reuss, "Berechnung der Fliessgrenze von Mischkristallen auf Grund der Plastizitätsbedingung für Einkristalle," $Z$. Angew. Math. Mech., 9, 49-58 (1929).

24. H. Neerfeld, "Zur Spannungsberechnung aus röntgenographischen Dehnungsmessungen," Mitt. Kaiser-Wilhelm-Inst. Eisenforschung Düsseldorf, 24, $61-70$ (1942).

25. R. Hill, "The elastic behaviour of a crystalline aggregate," Proc. Phys. Soc., 65, 349-354, (1952).

26. S. W. Tsai and H. T. Hahn, Introduction to Composite Materials, Technomic Publ. Co., Inc., Lancaster, Pennsylvania (1980).

27. K. Tanaka and T. Mori, "The hardening of crystals by non-deforming particles and fibers," Acta Metall., 18, 931-941 (1970).

28. T. Mori and K. Tanaka, "Average stress in matrix and average elastic energy of materials with misfitting inclusions," Acta Metall., 21, 571-574 (1973).

29. J. D. Eshelby, "The determination of the elastic field of an ellipsoidal inclusion, and related problems," Proc. Roy. Soc. London, A241, 376-396 (1957).

30. E. Kröner, "Berechnung der elastischen Konstanten des Vielkristalls aus des Konstanten des Einkristalls," Z. Phys., 151, 504-518 (1958).

31. F. Jacquemin, S. Fréour, and R. Guillén, "A self-consistent approach for transient hygroscopic stresses and moisture expansion coefficients of fiber-reinforced composites,” J. Reinf. Plast. Compos., 24, 485-502 (2005).

32. A. C. Loos and G. S. Springer, Environmental Effects on Composite Materials, Moisture Absorption of Graphite - Epoxy Composition Immersed in Liquids and in Humid Air, Technomic Publ. (1981), pp. 34-55.

33. A. Morawiec, "Calculation of polycrystal elastic constants from single-crystal data," Phys. Stat. Solidi (b), 154, 535-541 (1989).

34. S. Matthies and M. Humbert, "The realization of the concept of a geometric mean for calculating physical constants of polycrystalline materials," Phys. Stat. Solidi (b), 177, K47-K50 (1993).

35. S. Matthies, M. Humbert, and Ch. Schuman, "On the use of the geometric mean approximation in residual stress analysis,” Phys. Stat. Solidi (b), 186, K41-K44 (1994).

36. U. F. Kocks, C. N. Tome, and H. R. Wenk, Texture and Anisotropy, Cambridge Univ. Press (1998).

37. S. Fréour, F. Jacquemin, and R. Guillén, "On the use of the geometric mean approximation in estimating the effective hygro-elastic behaviour of fiber-reinforced composites,” J. Mater. Sci., 47, 7537-7543 (2007).

38. R. Morris, "Elastic constants of polycrystals," Int. J. Eng. Sci., 8, 49, (1970).

39. R. Hill, "Continuum micro-mechanics of elastoplastic polycrystals," J. Mech. Phys. Solids, 13, 89-101 (1965).

40. T. Mura, Micromechanics of Defects in Solids, Martinus Nijhoff Publishers, The Hague, Netherlands (1982).

41. K. S. Sai Ram and P. K. Sinha, "Hygrothermal effects on the bending characteristics of laminated composite plates," Comput. Struct., 40, No. 4, 1009-1015 (1991).

42. F. Jacquemin and A. Vautrin, "A closed-form solution for the internal stresses in thick composite cylinders induced by cyclical environmental conditions," Compos. Struct., 58, 1-9 (2002). 
43. S. Fréour, F. Jacquemin, and R. Guillén, "On an analytical self-consistent model for internal stress prediction in fiber-reinforced composites submitted to hygro-elastic load,” J. Reinf. Plast. Compos., 24, 1365-1377 (2005).

44. U. Welzel, S. Fréour, and E. J. Mittemeijer, "Direction-dependent elastic grain-interaction models - a comparative study," Philos. Mag., 85, 2391-2414 (2005).

45. O. Gillat and L. J. Broutman, "Effect of external stress on moisture diffusion and degradation in a graphite-reinforced epoxy laminate," in: ASTM STP 658 (1978), pp. 61-83.

46. Y. Weitsman, “A continuum diffusion model for viscoelastic materials," J. Phys. Chem., 94, 961-968 (1990).

47. Y. Weitsman, "Moisture in composites: sorption and damage," in: K. L. Reifsnider (ed.), Fatigue of Composite Materials, Elsevier Science Publ. (1990), pp. 385-429. 